\title{
ANALISIS ISTINBATHUL AHKAM TERHADAP FATWA MUI TENTANG PENYELENGGARAAN SHALAT JUM'AT DAN JAMAAH UNTUK MENCEGAH PENULARAN WABAH COVID 19
}

\author{
Ahmad Sanusi, Dian Febrifani, Usman Mustofa, Edy Setyawan \\ Faculty of Sharia UIN SMH Banten, UIN SMH Banten, UIN SMH Banten, \\ Fakultas Syariah dan Ekonomi Islam IAIN Syekh Nurjati Cirebon \\ Email: ahmad.sanusi@uinbanten.ac.id, dian.febriyani@uinbanten.ac.id, \\ usmanmusthafa@gmail.com, edysetyawano78@gmail.com
}

\begin{abstract}
Abstrak
Komisi Fatwa Majelis Ulama Indonesia telah mengeluarkan fatwa Nomor no 31 tahun 2020 Teantang Penyelenggaraan Shalat Jumat dan Jamaah Untuk mencegah Penularan Wabah Covid 19. Secara umum MUI sudah menyusun Pedoman Penetapan Fatwa Majelis Ulama Indonesia Nomor: U596/MUI/X/1997. Dalam pedoman tersebut disebutkan bahwa setiap

fatwa harus berupa pendapat hukum yang mempunyai dasar-dasar paling kuat dan membawa maslahat bagi umat. Dasar dasar yang dijadikan pegangan dalam melahirkan fatwa adalah al-Quran, hadits, ijma', qiyas dan dalil-dalil hukum lainnya.. namun demikian ada masalah dalam fatwa itu yaitu bagaimana bristidlal dan beristinbath al ahkam dalam fatwa tersebut. Makalah ini menjelaskan analisis istinbathul ahkam terhadap fatwa MUI di atas serta apa implikasi fatwa tersebut. Penelitian ini bersifat kualitatif dengan metode deskripsi analisis. Makalah ini merupakan hasil penelitian literatur. Hasil dari penelitian ini adalah pertama: pertama: Istidlal atau Istinbathul ahkam yang dilakukan MUI dalam mengeluarkan fatwa no. 31 tahun 2020 adalah: sebagai berikut: Pertama Ayat al Al Quran surah al Jumu'ah ayat 9, al Baqarah ayat 43, an nisa 102, al Hajj ayat 77, al Baqarah ayat 195 dan 185, al haj ayat 78, at Thagabun 16, ayat -ayat di atas kebanyakan terkait dengan kewajiban shalat Jum'at dan wajibnya Shalat serta adanya rukhsah dan keringanan dalam Islam, serta menjelaskan bahwa Allah Swt menghendaki kemudahan dalam melaksanakan beribadah bukan menyulitkan atau memberatkan dalam menjalankan ibadah bagi mukallaf.Kedua Hadis, yakni hadis Riwayat Abu dawud, hadis Riwayat Bukhari, Riwayat Ibnu Majah, Riwayat Muslim, Riwayat Baihaqi, Riwayat Ahmad, Riwayat ad Daruquthni, al baihaqi dan al hakim, ketiga: Atsar Sahabat yakni bersumber dari Riwayat musonnaf Abdurrazaq as shon'aniKeempat: Qaidah Fiqhiyah yakni ada enam kaidah fiqhiyah yang intinya terkait adanya keringanan dalam beribadah selagi ada hajat atau ada kebutuhan atau kedharuratan Keenam: Pendapat para ulama. Yakni ar Ramli dari madzhab Syafei, Ibnu Alan Ash Shiddiqi al Syafei, dari madzhab Syafei, al Kasani dari madzhab Hanafi, Syaikh Ibnu Abidin dari madzhab Hanafi, Imam Nawawi dari madzhab Syafei, Syaikh al Murawad, Syaikh Muhammad Syamsul Haq Abadi, Imam Nawawi dari madzhab Syafei, imam al Mawardi dari madzhab Syafei, Imam Nawawi dari madzhab Syafei, Syaikh Manshur al Bahuty. Dari urutan di atas sebenarnya dapat dikatakan bahwa fatwa tersebut sudah memenuhi syarat dalam beristidlal sesuai dengan pendapat jumhur ulama.
\end{abstract}

Keywords: Istinbathul ahkam, metode ijtihad, fatwa, hukum, 


\begin{abstract}
The Fatwa Commission of the Indonesian Ulema Council has issued fatwa Number 31 of 2020 concerning the Implementation of Friday Prayers and Jama'ah to prevent the transmission of the Covid 19 pandemic. In that case, every fatwa must be an opinion that has a strong argument and brings benefits to the people. The basic basis used as guidance in producing fatwas is the Koran, hadith, ijma', qiyas and other legal arguments. However, there is a problem in the fatwa, namely how to practice and practice al-ahkam in the fatwa. This paper explains the istinbathul ahkam analysis of the MUI fatwa above and what the implications of that fatwa are. This research is qualitative with the descriptive analysis method. This paper is the result of literature research. The results of this study are first: The first verse of the Al-Quran surah al-Jumu'ah verse 9, al-Baqarah verse 43, an-Nisa 102, alHajj verse 77, al-Baqarah verses 195 and 185, al-Hajj verse 78, at-Thagabun 16, the verses above are mostly related with the obligation of Friday prayers and obligatory prayers as well as the existence of rukhsah and relief in Islam, as well as explaining that Allah SWT wants ease in carrying out worship, not making it difficult or burdensome in carrying out worship for mukallaf; second, History of Ibn Majah, History of Muslim, History of Baihaqi, History of Ahmad, History of ad Daruquthni, al-Baihaqi and al-Hakim; third: Atsar Sahabat which is sourced from the history of musonnaf Abdurrazaq as-Shon'an; fourth: Qaidah Fiqhiyah, namely there are six fiqhiyah principles which are related to the relief of worship while there is a need or need or emergency; and sixth: Opinions of the scholars. Namely ar-Ramli from the Syafei school, Ibn Alan Ash-Shiddiqi al-Syafei, from the Syafei school, al-Kasani from the Hanafi school, Shaykh Ibn Abidin from the Hanafi school, Imam Nawawi from the Syafei school, Shaykh al-Murawad, Shaykh Muhammad Syamsul Haq Abadi, Imam Nawawi from Syafei school, Imam al-Mawardi from the Syafei school, Imam Nawawi from the Syafei school, Syaikh Manshur al-Bahuty. From the above sequence, it can be said that the fatwa has met the requirements for doing istidlal by the opinion of the Jumhur ulama.
\end{abstract}

Keywords: Istinbathul ahkam, ijtihad method, fatwa, law 


\section{A. PENDAHULUAN}

Fatwa adalah salah satu bentuk pendapat yang dikeluarkan oleh seorang ulama atau beberapa ulama kepada orang atau masyarakat yang bertanya tentang hukum Islam atau etika atau adab yang terkait hukum Islam, fatwa biasanya dikeluarkan karena adanya keresahan masyarakat muslim tentang hukum sesuatu yang belum diketahui oleh masyarakat atau orang yang awam tentang hukum Islam, dalam fatwa bisa saja masalah yang ringan menurut Sebagian orang akan tetapi juga berat menurut Sebagian orang lainnya karena keawaman dan ketidak tahuannya, seperti misalnya ada orang meminta fatwa bagaimana cara berwudhu, dalam hal ini pertanyaan seperti itu kelihatan ringan, akan tetapi bagi orang yang awam atau bagi orang baru masuk Islam ini bisa jadi dia tidak mengetahui bagaimana cara berwudhu yang benar sesuai dengan hukum Islam. Namun ada juga fatwa yang berat dan harus banyak mengeluarkan tenaga dalam membahasnya dan mengeluarkan fatwanya dan juga diperlukan oleh sekelompok ulama karena memang berat dan sulit masalah fatwa itu, seperti ada sekelompok masyarkat muslim yang bertanya bolehkah memilih pemimpin non muslim? Fatwa ini dibahas oleh banyak ulama karena memang materi pertanyaan fatwanya agak berat serta juga berkaitan dengan kepentingan orang banyak maka seyogyanya para ulama atau para mufti sebaiknya ia berhati-hati dalam mengeluarkan fatwanya karena hal itu bisa saja impiliksainya tidak baik bila fatwa itu dikelurkan tidak dengan ilmu dan sembrono.

Fatwa kalau di lihat dari sejarahnya sudah ada dari masa nabi dulu, Syaikh Mahmud Syaltut mantan Syaikhul Azhar Mesir dalam bukunya al Fatawa ${ }^{1}$, beliau menjelaskan bahwa

1 Mahmud Syaltut, al fatawa dirosah $l i$ musykilatil muslim al muashir fi hayatihi al yaumiyah wal ammah (Mesir: Dar al Qalam, tth) cet. Ke 3 hlm5 fatwa adalah manhaj qurani, yakni metode yang dilakukan al Quran dalam menjawab permasalahan yang ditanyakan para sahabat kepada Nabi Muhammad Saw. dan turunlah ayat al Quran mengenai hal itu, dan dengan demikian bisa dikatakan bahwa fatwa adalah metode lama yang sudah ada semenjak masa nabi, hanya saja perlu diingat bahwa fatwa di masa itu langsung dijawab oleh Pembuat Syariah yaitu Allah dan Rasulnya maka kekuatan fatwa itu adalah kuat dan pasti serta menjadi qath'I, hal itu berbeda dengan fatwa yang dikeluarkan ulama pada masa sesudah nabi dan masa kini kekuatannya tidak sekuat di atas akan tetapi setidaknya mendekati.

Menurut Syaltut bahwa fatwa di dalam al Quran memiliki dua manhaj, yaitu: Pertama: fatwa yang tidak didahului pertanyaan, yaitu di antaranya mengarahkan perintah dan larangan contohnya adalah sebagai berikut:

Surat al Baqarah ayat 183 sebagai berikut:

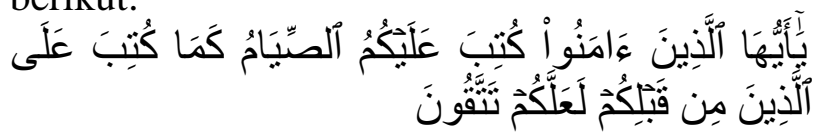

Artinya: Hai orang-orang yang beriman, diwajibkan atas kamu berpuasa sebagaimana diwajibkan atas orang-orang sebelum kamu agar kamu bertakwa (Q.s.: al Baqarah : 183)

Dan juga Surat al Baqarah ayat 178:

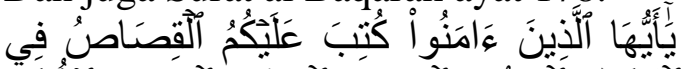

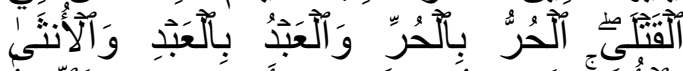

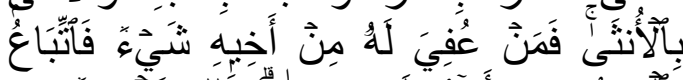

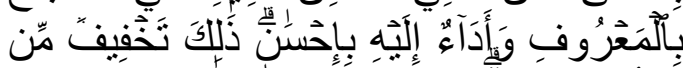

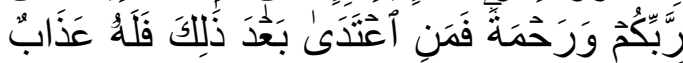

Artinya: Hai orang-orang yang beriman, diwajibkan atas kamu qishaash berkenaan dengan orangorang yang dibunuh; orang merdeka dengan orang merdeka, hamba dengan hamba, dan wanita dengan wanita. Maka barangsiapa yang mendapat suatu pemaafan dari saudaranya, hendaklah (yang memaafkan) mengikuti 
dengan cara yang baik, dan hendaklah (yang diberi maaf) membayar (diat) kepada yang memberi maaf dengan cara yang baik (pula). Yang demikian itu adalah suatu keringanan dari Tuhan kamu dan suatu rahmat. Barangsiapa yang melampaui batas sesudah itu, maka baginya siksa yang sangat pedih ( Q. s: al Baqarah: 178)

Dari ayat-ayat di atas jelaslah bahwa Allah Swt menurunkan ayat dengan perintah kepada kaum muslim untuk berpuasa dan juga untuk menerapkan hukum Qisas walaupun tanpa di dahului oleh pertanyaan dari para sahabat.

Kedua: Fatwa yang didahului pertanyaan, dalam hal ini penjelasanya selalui didahului oleh sebuah pertanyaan. Dan ini adalah penjelasan yang memang sebelumnya belum ada penjelasan tentang hukumnya, maka para sahabat menanyakan hukumnya agar lebih jelas dan diketahui hukumnya dalam Islam. Dan Al quran banyak merekam beberapa pertanyaan kepada Rasulullah Saw dan kemudian disertai jawabanya, dan Adapun di antara contohnya adalah sebagai berikut:

Ada seorang Arab pedalaman bertanya kepada Rasul Saw. apakah tuhan kita itu dekat maka saya akan memintanya ataukah tuhan kita itu jauh maka saya akan memanggilnya, maka turunlah surat al Baqarah ayat 186:

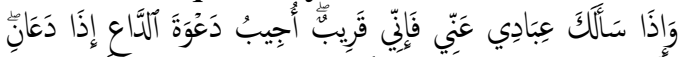

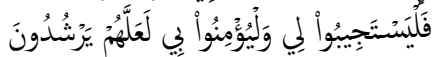

Artinya: Dan apabila hamba-hamba-Ku bertanya kepadamu tentang Aku, maka (jawablah), bahwasanya Aku adalah dekat. Aku mengabulkan permohonan orang yang berdoa apabila ia memohon kepada-Ku, maka hendaklah mereka itu memenuhi (segala perintah-Ku) dan hendaklah mereka beriman kepada-Ku, agar mereka selalu berada dalam kebenaran (Q.s: al Baqarah: 186)

Contoh lainnya adalah para sahabat hidup di kota Madinah yang terdiri dari dua kelompok yaitu orang muslim dan ahlil kitab dari Yahudi Madinah kemudian ada Sebagian kelompok yang menggauli isterinya pada saat haidh dan kelompok lain ada yang menjauhkan isterinya pada saat haidh dengan ditempatkan jauh dari rumahnya Ketika isterinya haid, maka para sahabat bertanya kepada Rasul Saw. ${ }^{2}$ maka turunlah surat al Baqarah ayat 222 sebagai berikut:

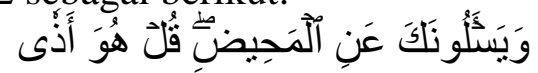

Artinya: Mereka bertanya kepadamu tentang haidh. Katakanlah: "Haidh itu adalah suatu kotoran". (Q.s: al Baqarah: 222)

Demikianlah Fatwa pada masa nabi, kemudian setelah itu masa sahabat fatwa berkembang dan sampai masa kita ini berkembang mengikuti zaman tempat dan waktu.

Komisi Fatwa MajelisUlama Indonesia telah mengeluarkan fatwa Nomor no 31 tahun 2020 Teantang Penyelenggaraan Shalat Jumat dan Jamaah Untuk mencegah Penularan Wabah Covid 19. Secara umum MUI sudah menyusun Pedoman Penetapan Fatwa Majelis Ulama Indonesia Nomor: U596/MUI/X/1997. Dalam pedoman tersebut disebutkan bahwa setiap fatwa harus berupa pendapat hukum yang mempunyai dasar-dasar paling kuat dan membawa maslahat bagi umat. Dasar dasar yang dijadikan pegangan dalam melahirkan fatwa adalah al-Quran, hadits, ijma', qiyas dan dalil-dalil hukum lainnya. ${ }^{3}$

Pada hakikatnya, kemunculan hukum-hukum Islam itu adalah dimaksudkan untuk menjaga kemuliaan manusia dan memelihara kepentingan, baik yang bersifat khusus maupun umum. Syariat-syariat langit menentukan ada lima kebutuhan yang berisikan: Menjaga kehidupan manusia dengan mengharamkan membunuhnya,

\footnotetext{
${ }^{2}$ Mahmud Syaltu Ibid hlm.10

${ }^{3}$ Pedoman Penyelenggara Organisasi Majelis Ulama Indonesia, 18
} 
menjaga kehormatanya, menjaga akalnya, menjaga hartanya, dan menjaga agamanya. Syariat Islam adalah merupakan syariat terakhir yang membawa petunjuk bagi umat manusia. Dengan syariat itu Allah telah memberikan beberapa keistimewaan, antara lain; hal-hal yang bersifat umum, abadi dan meliputi segala bidang. Di dalamnya telah diletakkan dasar-dasar hukum bagi manusia dalam memecahkan segala permasalahan.

Walaupun MUI memiliki basis dukungan yang kuat dari umat. Proses pengambilan hukumnya melalui ijtihad kolektif Ulama Indonesia. Semua itu hanya bersifat masukan positif dan aspirasi umat Islam kepada pemerintah. Perlu ada sinergisitas antara pemerintah dan Majelis Ulama Indonesia yang nota bene adalah perwakilan dari simbol umat Islam Indonesia. Sehingga bagaimana pun fatwa MUI menjadi petunjuk bagi umat apalagi terkait eksistensi hidup dan kebutuhan manusia yang tampak dalam fatwa-fatwa MUI yang beradasarkan kemaslahatan umum.

Berdasarkan latar belakang di atas, tulisan ini akan membahas tentang bagaimana analisis istinbathul ahkam dalam fatwa MUI sehingga bisa diungkap secara kritis bagaimana landasana hukum yang telah disistemasikan oleh para ulama ushul dan bagaimana implikasinya dalam masyarakat Islam di Indonesia di masa pandemic Covid 19 yang belum berhenti sampai sekarang ini.

\begin{tabular}{cccc}
\multicolumn{2}{c}{ Organisasi } & Majelis & Ulama \\
Indonesia & (MUI) & seolah & ingin
\end{tabular} mengukuhkan diri sebagai pemilik otoritas tunggal pembuat keputusankeputusan keagamaan bagi umat Islam Indonesia. Melalui majelis Fatwanya, MUI telah berhasil menjawab problematika umat termasuk dalam persoalan yang menyangkut nyawa dan kebutuhan manusia dengan metode Ihtihadnya.

\section{Perumusan Masalah}

Pokok permasalahannya sebagaimana diungkapkan pada latar belakang di atas adalah "Bagaimana Analisis Istinbathul ahkam terhadap Fatwa MUI tentang Penyelenggaraan Shalat Jumat dan Jamaah untuk mencegah penularan Covid 19 “

\section{Kegunaan Penelitian}

Penelitian ini diharapkan dapat memberikan dua aspek kegunaan yaitu: kegunaan dari aspek akademis dan kegunaan dari aspek praktis. Dari aspek akademis penelitian ini diharapkan memberikan kontribusi dalam pengembangan studi hukum Islam khususnya bagi pengembangan ilmu Syariah dan tentu saja hal ini sangat bermanfaat bagi Fakulas Syariah, karena dengan berkembangnya ilmu kesyariahan maka berkembangn pula fakultas Syariah dengan di bawah pemahaman Islam yang moderat. Dari segi praktis penelitian ini daiharapkan dapat berguna bagi pengguna kebijakan dalam memutuskan hal yang terkait dengan kebijakan terkait pelaksanaan ibadah.

\section{Metodologi Penelitian}

Penelitian ini bersifat kualitatif dengan metode deskripsi analisis. Sumber data yang digunakan terdiri dari sumber data primer, skunder, dan tertier. Sumber data primer ini bersifat dokumenter, yaitu dengan mengurnpulkan dokumen-dokumen resmi berkaitan dengan fatwa Majelis Ulama Indonesia Ditambah dengan buku-buku yang berkaitan dengan masalah yang diteliti.

Pengumpulan dan pengolahan data menggunakan studi Pustaka dan sedikit studi lapangan dengan tehnik interview dan observasi. Studi Pustaka digunakan untuk mengumpulkan data dan informasi dalam bentuk kepustakaan terutama yang terkait dengan penelitian.

\section{B. HASIL PENELITIAN DAN PEMBAHASAN}

Metode secara bahasa berarti cara sedangkan maksud metode di sini 
adalah suatu cara yang teratur yang digunakan untuk melaksanakan suatu hal agar tercapai tujuan sesuai yang dikehendaki. Sedangkan istinbathul ahkam berarti perumusan masalah hukum. Istinbath adalah berasal dari kata bahasa Arab yang berarti mengeluarkan atau menetapkan. Sedangkan secara istilah intinbath adalah daya usaha yang harus diupayakan untuk merumuskan hukum syara berdasarkan al Quran dan hadis melalui jalan ijtidah. Jadi yang dimaksud metode Istinbath hukum di sini adalahaturan atau pedoman dalam merumuskan hukum Islam atau hukum syara'

\section{Sumber-sumber hukum Islam}

Sumber-sumber hukum Islam atau mashodirul ahkam pada bentuk asalnya terbagi menjadi dua:

Pertama sumber tekstual atau sumber tertulis atau juga disebut dengan an nushus yaitu langsung berdasarkan al Quran dan Sunnah Nabi

Kedua: Sumber non tektual atau sumber tak tertulis atau biasa disebut juga dengan Ghairu nushus, yaitu seperti Istihshan Qiyas, istishab, al maslahah dan lain-lain, meskipun sumber hukumnya tidak langsung mengambil dari al Quran dan Hadis tapi hakikatnya digali dari (berdasarkan atau menyandar ) pada al Quran dan al Hadis.

\section{Macam -macam Metode Istinbath hukum}

Setelah dijelaskan di atas mengenai sumber hukum Islam dapatlah disimpulkan bahwa pada dasarnya metode pemahaman hukum Islam yang berangkat melalui pemahaman langsung dari teks disebut lafdziyah. Sedangkan pemahaman tidak langsung dari teks disebut maknawiyah.

Dengan demikian dapat dikatakan bahwa metode istinbath hukum itu terbagi menjadi dua metode yaitu metode kebahsaan (thariqoh lughowiyah) dan maknawi (thariqoh maknawiyah). Berikut ini penulis akan jelaskan kedua metode Istinbath hukum tersebut.

Pertama: Istinbathul al Thariqoh al Lughowiyah

Lafal ditinjau dari segi bentuk Perintah dan larangan Asy Syari'

1. Al Amr

2. An Nahy

Lafal ditinjau dari Segi Tingkat Kejelasan Makna

a. Lafal yang samar maknanya (khafi ad dilalah)

Lafazh yang ghairu wadhih (yang tidak jelas maknanya). Menurut mazhab Hanafi terdiri dari empat macam, yaitu:

1. Khafiy.

2. Musykil.

3. Mujmal, dan

4. Mutasyabih.

Pembagian ini didasarkan pada peringkat kesamarannya yang berbeda. Yang terkuat kesamarannya adalah mutasyabih, lawan dari muhkam. Berikutnya adalah mujmal, lawan dari mufassar. Selanjutnya musyakil, lawan dari nash. Terakhir adalah khafi, lawan dari zhahir.

Selanjutnya, kesamaran yang terdapat pada gahiru wadhih adakalanya berasal dari lafazh itu sendiri dan hanya Allah sejarah yang mengetahuinya, seperti potonganpotongan huruf pada awal surat Al-Qur'an. Ayat-ayat semacam itu tidak ditemukan penjelasannya dari nash Al-Qur'an maupun sunnah, dan karenanya ia tidak pula masuk dalam pentaklifan manusia. Inilah yang disebut mutasyabih. Dengan demikian, mutasyabih tidak dapat ditangkap dengan akal maupun naqal (Al-qur'an dan Sunnah).

Kemudian ada kalanya ditemukan penjelasannya dari Al-Qur'an atau sunnah yang dapat menghilangkan kesamarannya, karena sebagian alquran menafsirkan sebagian yang lain, dan sunnah menafsirkan Alquran. Lafazh yang tidak jelas (yang kemudian ditafsirkan secara jelas ini). Disebut mujmal. Kemudian jika kesamarannya terdapat pada lafazh itu sendiri, akan tetapi maknanya masih dapat ditangkap dengan penalaran dan kajian yang srius, maka di sebut musyakil. Selanjutnya adakalanya kesamaran itu datang dari luar 
lafazh itu, yang menyangkut penerapannya terhadap hal lain yang memiliki kemiripan dengan hal yang disebutkan dalam lafazh. Lafazh semacam ini disebut khafi.

\section{Dilalah lafal menurut Syafiiyah:}

Dalalah suatu lafazh yang terdapat dalam Al-Qur'an dan Sunnah terhadap hukum syara' menurut ulama usul dari kalangan Syafi'iyyah atau jumhur mutakallaimin selain kalangan mazhab Hanafi terbagi kepada dua macam, yaitu: manthuq dan mafhum. Sementara itu, alAmidi mengemukakan versi lain lagi, yaitu: dalalah manzhum dan dalalah ghairu manzhum.

\section{Dilalatul Manthuq}

Pengertian Manthuq: Manthuq berasal dari bahasa Arab sebagai konjugasi dari kata natahaqa yang berarti berkata atau berbicara, Manthuq berarti sesuatu yang dikatakan atau dibicarakan.

Manhtuq menurut istilah ulama ushul fiqh ialah: suatu makna yang ditunjuk langsung oleh lafazh yang diucapkan oleh si pengucapannya. Manthuq ini terbagi dua, yaitu: manthuq yang tidak memiliki kemungkinan untuk ditakwilkan, yang disebut nash, dan manthuq yang memiliki kemungkinan untuk ditakwilkan, atau mengandung makna yang marjuh (lemah) disamping makna yang rajih (lebih kuat) yang disebut zhahir.

\section{Dilalatul Mafhum}

Mahfum berasal dari kata fahima yang berarti: mengerti dan paham. Mahfum berarti: sesuatu yang dimengerti dan dipahami. Mahfum menurut istilah ushul fiqh ialah: makna yang tidak langsung ditunjuki oleh lafazh yang diucapkan. Dengan kata lain. Mahfum ialah: dalalah lafazh terhadap hukum sesuatu yang tidak disebutkan dalam kalimatnya, akan tetapi dalalah itu dipahami darinya.

Mafhum Muwafaqah yaitu: dalalah lafazh terhadap tetapnya hukum sesuatu yang disebutkan dalam lafazh itu, karena lafazh bagi sesuatu yang tidak disebutkan dalam lafazh itu, karena kesamaan 'illat hukum yang dipahami secara kebahasan. Disebut muwafaqah, karena makna dan dalalah hukum yang dipahami untuk kasus lain sejalan dan sesuai dengan apa yang dinyatakan secara eksplisit dalam nash, Dalam mazhab Hanafi mafhum muwafaqah ini disebut dalalah al-nash, ia juga disebut fahwa al-khithab.Misalnya, firman Allah swt.

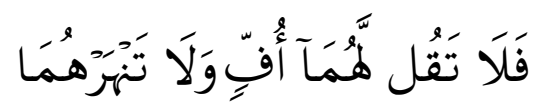

"Maka sekali-kali janganlah kamu mengatakan kepada keduanya perkataan "ah" dan janganlah kamu membentak mereka."

Makna manthuqnya ialah keharaman mengucapkan perkataan "ah" dan membentak ibu dan bapak. Kemudian dari ayat itu dipahami bahwa memukul mereka juga haram, bahkan lebih berat keharamannya dibandingkan sekedar berkata "ah". Misalnya lagi. Firman Allah swt:

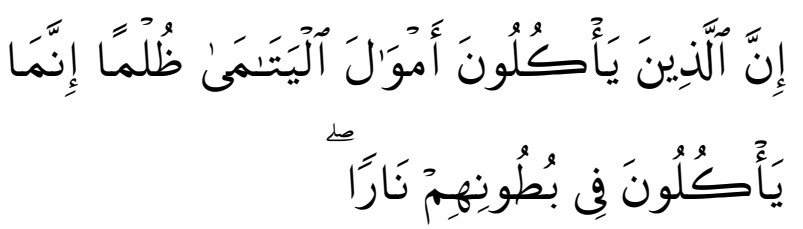

"Sesungguhnya orang-orang yang memakan harta anak yatim secara zalim, Sebenarnya mereka itu menelan api sepenuh perutnya."

Makna manthuq ayat tersebut menunjukan keharaman memakan harta anak yatim secara zalim. Dari ayat itu juga dipahami, bahwa memusnahkan harta anak yatim juga haram hukumnya. Keharaman ini sama dengan keharaman memakannya secara zalim.

Mafhum Mukhalafah, yaitu: Menetapkan kebalikan hukum yang terdapat pada manthuq bagi sesuatu yang tidak disebutkan dalam lafazh itu. Penetapan kebalikan itu disebabkan tidak adanya batasan (qqayad) yang membatasi manthuq pada sesuatu yang tidak disebutkan itu. Penyebutan mukhalafah disebabkan bahwa makna atau bertentangan dengan hukum dan makna 
yang terdapat pada lafazh yang diucapkan. Mahfum ini disebut juga dalil al-khithab.

Kedua: Istinbathul al Thariqoh al Maknawiyah

Qiyas

Qiyâs menurut bahasa Arab berarti menyamakan, membandingkan atau mengukur, seperti menyamakan si A dengan si $\mathrm{B}$, karena kedua orang itu mempunyai tinggi yang sama, bentuk tubuh yang sama, wajah yang sama, dan sebagainya. Qiyâs juga berarti mengukur, seperti mengukur tanah dengan meter atau alat pengukur yang lain. Demikian pula membandingkan sesuatu dengan yang lain dengan mencari persamaan-persamaannya. Dengan demikian, qiyâs diartikan mengukurkan sesuatu atas yang lain agar diketahui persamaan antara keduanya. $^{4}$

Sedangkan secara istilah, Saifuddin AlAmidi mendefinisikan bahwa qiyâs adalah:

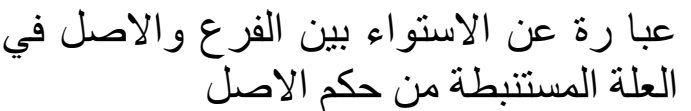

"Mempersamakan illat yang ada pada furu' dengan illat yang ada pada asal yang diistinbatkan dari hukum asal." 5

Secara etimologi, istihhsân berarti "menyatakan dan meyakini baiknya sesuatu." Tidak terdapat perbedaan pendapat ulama ushûl fiqh dalam mempergunakan lafal istihsân dalam pengertian etimologi. ${ }^{6}$ Karena lafal yang seakar dengan istihlsân banyak dijumpai dalam AlQur'an dan Sunnah Rasulullah Saw. misalnya, dalam surat al-Zumar (39:18), Allah berfirman:

${ }^{4}$ Lihat Ibnu Mandzur, Lisanul Arab, (Beirut: Dar al Fikr,1972), Bab Sin, Juz. 6, h. 354. Dalam Kitabkitab Ushul Fiqh, Qiyas menurut bahasa hampir sama mengartikannya yaitu mengukur sesuatu dengan yang lain (lihat Nasrun Harun,Ushul Fiqh 1, (Jakarta: Logos.1996), cet. 1, h. 62.

${ }^{5}$ Saif al din Al Amidi, Al Ihkam Fi Ushul al Ahkam, (Beirut: Dar al Fikr,1996), Jilid 3, h. 2.

${ }^{6}$ Lihat al-Sarakshi, Ushul al-Sarakhshi, (Beirut: Dar al-Kutub al-'Ilmiyyah, 1993), Jilid II, h. 200, dan Saifuddin al-Amidi, op. cit., Jilid III, hal. 126.
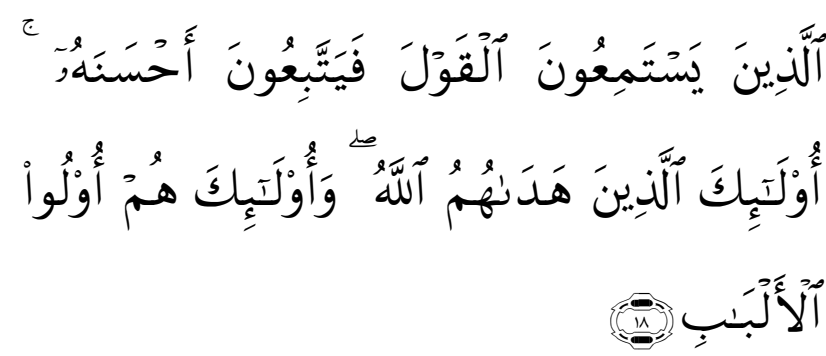

"Yang mendengarkan perkataan lalu mengikuti apa yang paling baik di antara mereka, itulah orang-orang yang telah diberi Allah petunjuk dan mereka itulah orang-orang yang mempunyai akal."

Kemudian dalam sebuah riwayat dari 'Abdullah ibn Mas'ud Rasulullah Saw. bersabda:

$$
\text { مار آه المسلمون حسنا فهو عند الله حسن }
$$

"Sesuatu yang dipandang baik oleh umat Islam, maka di sisi Allah itu juga baik." (H.R. Ahmad ibn Hanbal).

Di samping itu, para mujtahîd juga sering menggunakan istihsân dalam pengertian etimologi ini, seperti ucapan Imam Aš-Šafi' ${ }^{1}{ }^{7}$

المتعة

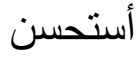

"Saya menganggap baik dalam persoalan hadiah (harta setelah terjadi talak sebesar 30 dirham)".

Kalimat saya menganggap baik memberikan hak šuf'ah bagi As-Šafi'i sampai tiga hari. Oleh sebab itu, letak perbedaan pendapat sebenarnya dalam rumusan dan hakikat istihhsân.

Secara terminologi Imam al- Bazdawi (400-482 H/ 1010-1079 M), ahli Ushûl Fiqh Hanafi), ${ }^{8}$ mendefinisikan istihsân dengan:

العدول من قياس جلي الي قياس خفي لد ليل اقوي منه "Berpaling dari qiyâs yang lebih kuat ke qiyâs yang tersembunyi (illat) berdasarkan dalil yang lebih kuat."

\section{Analisis Istinbathul ahkam atau Istidlal dalam fatwa}

Adapun istidlal yang digunakan oleh Fatwa MUI no. 31 tahun 2020 ini adalah

Pertama Al Quran yaitu:

Firman Allah SWT:

7 Al-Banani, Syarh al-Mahalli 'ala Jam'I alJawami, op. cit., Jilid II, h. 288, dan al-Syarakhsi, loc. cit.

${ }^{8}$ Al-Sarakhsi, loc. cit. 


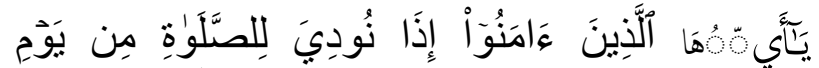

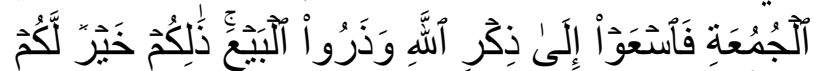

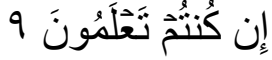

Artinya: Hai orang-orang yang beriman, apabila diseru untuk menunaikan shalat pada hari Jum'at, maka bersegeralah kamu kepada mengingat Allah dan tinggalkanlah jual beli. Yang demikian itu lebih baik bagimu jika kamu mengetahui”. (QS. alJumu'ah [62]: 9)

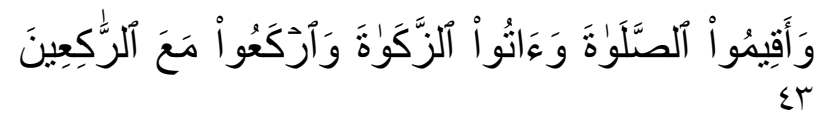

Artinya: Dan dirikanlah shalat, tunaikanlah zakat, dan ruku'lah bersama orang-orang yang ruku'." (QS. al-Baqarah [2]: 43)

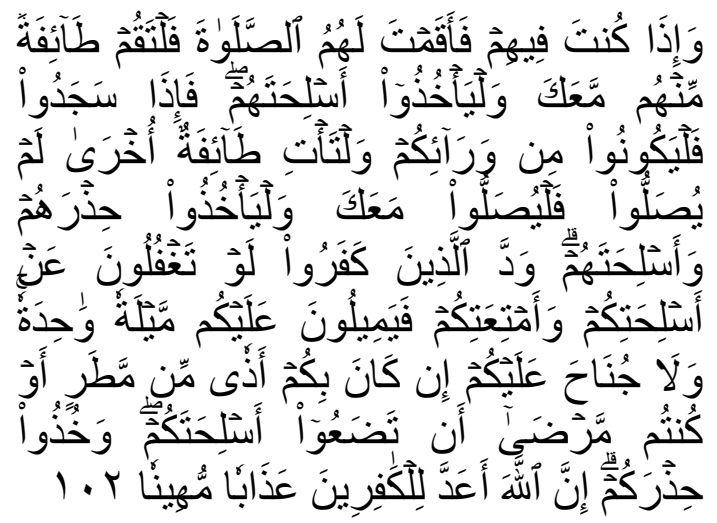

Artinya: "Dan apabila kamu berada di tengah-tengah mereka (sahabatmu) lalu kamu hendak mendirikan shalat bersamasama mereka, maka hendaklah segolongan dari mereka berdiri (shalat) besertamu dan menyandang senjata, kemudian apabila mereka (yang shalat besertamu) sujud (telah menyempurnakan satu raka'at), maka hendaklah mereka pindah dari belakangmu (untuk menghadapi musuh) dan hendaklah datang golongan yang kedua yang belum shalat, lalu shalatlah mereka bersamamu dan hendaklah mereka bersiap siaga dan menyandang senjata. Orang-orang kafir ingin supaya kamu lengah terhadap senjatamu dan harta bendamu, lalu mereka menyerbu kamu sekaligus. Dan tidak ada dosa atasmu meletakkan senjata-senjatamu, jika kamu mendapat sesuatu kesusahan karena hujan atau karena kamu memang sakit; dan siap-siagalah kamu. Sesungguhnya Allah telah menyediakan azab yang menghinakan bagi orangorang kafir itu." (QS. al-Nisaa' [4]: 102)

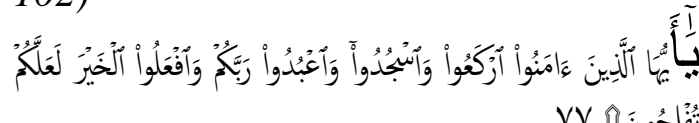

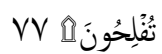

"Hai orang-orang yang beriman, ruku'lah kamu, sujudlah kamu, sembahlah Tuhanmu dan perbuatlah kebajikan, supaya kamu mendapat kemenangan." (QS. al-Haij [22]: 77)

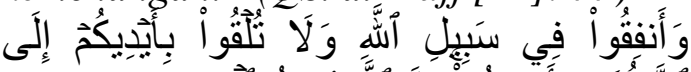

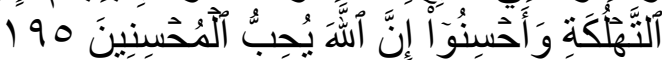
Dan janganlah kamu jatuhkan (diri sendiri) ke dalam kebinasaan dengan tangan sendiri, dan berbuat baiklah. Sesungguhnya Allah menyukai orangorang yang berbuat baik." (QS. alBaqarah [2]: 195)

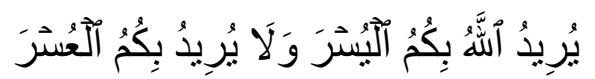

Allah menghendaki kemudahan bagimu, dan tidak menghendaki kesukaran bagimu...... (QS. al-Baqarah [2]: 185)$$
\text { وَمَا جَعَلَ عَلَيَكُمْ فِي ألالِّينِ مِنْ حَرَجْ }
$$

dan Dia sekali-kali tidak menjadikan untuk kamu dalam agama suatu kesempitan ... (QS. al-Hajj [22]: 78)

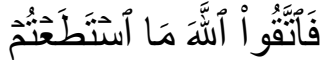

Maka bertakwalah kamu kepada Allah menurut kesanggupanmu ... . (QS. al-Taghabun [64]: 16) 2 .

Kedua: Hadis Rasulullah SAW, antara lain: :

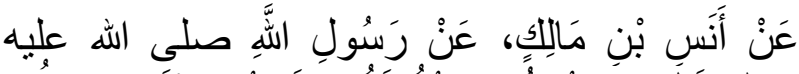

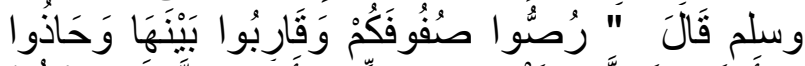

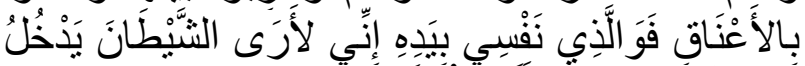

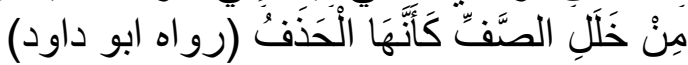

(Dari Anas bin Malik ra. dari Rasulullah Saw. bersabda: "Lekatkanlah/rapatkanlah barisan kalian dan saling berdekatlah dan tempelkan pundak-pundak kamu. Demi Dzat yang jiwaku berada dalam genggaman-Nya, sesungguhnya aku melihat syetan memasuki di antara sela- 
sela saf seperti Hadzaf (anak kambing hitam.jenis kambing yang berada di daerah Yaman )"(HR. Abu Dawud)

عن جابر بن عبد الله قال: قال رسول الله صلي الله عليه وسلم: اعطيت خمسا لم يعطهن احد من الآنبياء قبلي: نصرت بالرعب وسيرة شهرة وجعلت لي الارض مسجدا و طهورا, وايما رجل من من امتي ادركته الصلاة فليصل (رواه البخاري)

Dari Jabir bin Abdullah ra. berkata: Rasulullah Saw. bersabda: "Saya dikaruniai (oleh Allah) lima hal, yang belum pernah dikaruniakan kepada selain saya. Saya ditolong (dalam peperangan,sehingga) perasaaan musuh (dalam peperangan) menjadi gentar (menghadapi saya) dalam masa peperangan yang memakan waktu sekitar sebulan, bumi dijadikan sebagai tempat shalat dan suci bagi saya dan karenanya, siapa saja dari umatku yang mendapatkan waktu shalat, maka hendaklah dia shalat (di bumi mana saja dia berada), ... “. (HR. Bukhari)

عن ابن عباس، قال: قال النبي - صَلَّى اللهُ عَلَيَهِه

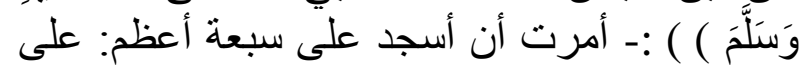

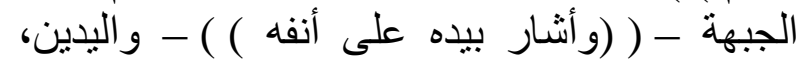

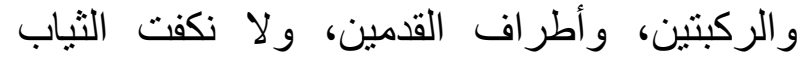

$$
\text { و الثعر (رو اه البخاري) و الطراف) }
$$

Dari Ibnu Abbas ra. berkata: Nabi Saw. bersabda: "Aku diperintahkan untuk sujud di atas tujuh anggota badan; kening (lalu beliau menunjuk juga pada hidungnya), kedua tangan, kedua lutut, dan kedua kaki, dan kami tidak (boleh) menahan pakaian dan rambut". (HR. Bukhari)

عن ابي هريرة قال: نهى رسول الله صلى الله عليه وسلم أن يغطي الرجل فاه في الصلاة (رواه (بن ماجها (بله

Dari Abu Hurairah ra. berkata: "Rasulullah Saw. melarang orang laki-laki untuk menutup mulutnya saat shalat". (HR. Ibnu Majah)

عن ابي هريرة رضي الله عنه سمع رَسُوْلَ اللهِ صِلى

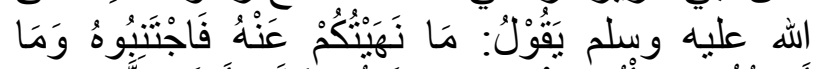

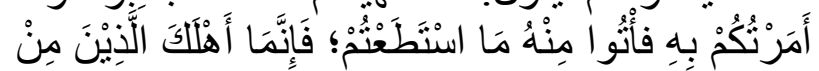

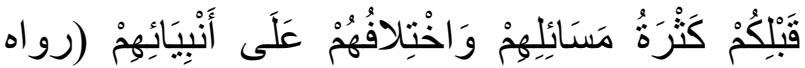

مسلم)

Abu Hurairah ra. mendengar Rasulullah Saw. bersabda: "Apa saja yang aku larang kamu melakukannya, hendaklah kamu jauhi, dan apa saja yang aku perintahkan kepadamu, maka lakukanlah menurut kemampuan kamu. Sesungguhnya kehancuran umat-umat sebelum kamu adalah karena mereka banyak bertanya dan tidak patuh dengan nabi-nabi mereka." (HR. Muslim)

عن ابن عمر ان رسول الله صلي الله عليه وسلم قال: إن الله عز وجل يحب أن تؤتى رئ رخصه كما يحب أن أن تؤتى عز ائمه

Dari Ibnu Umar ra. sesungguhnya Rasulullah Saw. bersabda: "Sesungguhnya Allah suka untuk dikerjakan rukhsah-Nya, demikian juga Allah suka untuk dikerjakan perintah-Nya (azimah)." (HR. al-Baihaqi)

عن ابن عمر قال: قال رسول الله -صلى الله عليه

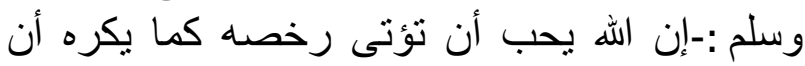
تؤتى معاصيه (رو اه احمد)

Dari Ibnu Umar ra. Rasulullah Saw. bersabda: "Sesungguhnya Allah suka untuk dilakukan rukhsah-Nya, sebagaimana Allah membenci apabila maksiat dilakukan." (HR. Ahmad)

عن أبي سعيد سعد بن ماللك بن سنان الخدري رضي

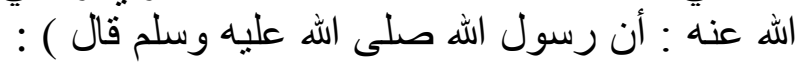
لا ضرر ولا لا ضرار(رواه الدارقطني والبيهقي و الحاكم)

Dari Abû Sa'îd Sa'd bin Mâlik bin Sinân alKhudri Radhyallahu anhu, Rasûlullâh Saw. bersabda, "Tidak boleh ada bahaya dan tidak boleh membahayakan orang lain". (HR. alDâraquthni, alBaihaqi, al-Hakim)

\section{Ketiga: Atsar sahabat}

عن ابن جريح قال: قلت لعطاء: ار ايت اهل البصرة

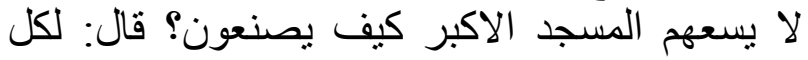

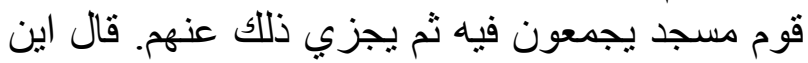

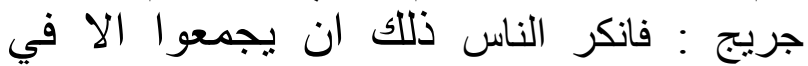
المسجد الاكبر (مصنف عبد الرزاق الصنعاني) 
Dari Ibnu Juraij: aku berkata kepada 'Atha: tidakkah kau lihat penduduk Bashrah? masjid besar di sana tak mampu lagi menampung mereka! lalu apa yg musti mereka perbuat? 'Atha menjawab: baiknya setiap penduduk daerah mempunyai masjid sendiri untuk mereka berkumpul didalamnya, maka hal tersebut sudah mencukupi (untuk didirikannya shalat Jum'at). Lalu mereka mengingkari fatwa 'Atha, dan tetap memilih mendirikan shalat di masjid besar tersebut."

\section{Keempat: Qaidah Fiqhiyyah}

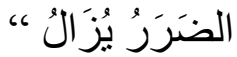

$$
\begin{aligned}
& \text { دُر "ُ المفاسد مقدم علي جلب المصالح }
\end{aligned}
$$

$$
\begin{aligned}
& \text { "المشقة تجلب التيسير". } \\
& \text { Kesulitan membawa kepada } \\
& \text { kemudahan" } \\
& \text { الضرر بدفع بقدر الامكان } \\
& \text { الضرورة تقد ر بقد رها } \\
& \text { مالا يد رك كله لا يترك كله }
\end{aligned}
$$

\section{Kelima: Pendapat para ahli fikih}

Pendapat fuqaha terkait dengan saf dalam shalat jamaah, antara lain: Pendapat al-Ramli dalam kitab Nihayah al-Muhtaj Ila Syarh al-Minhaj (2/192):
وسئل الثهاب الرملي عما افتي به بعض اهل اهل أنه

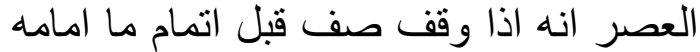

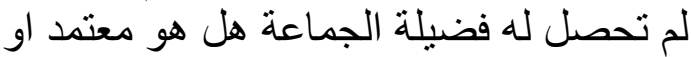
لا؟ فاجاب بانه لا تفوته فضيلة الجماعة بوقوفه المذكور

Syihab al-Ramli pernah ditanya tentang fatwa sebagian ulama tentang kuat atau tidaknya pendapat bahwa jika seorang jamaah yang membuat saf baru sebelum sempurnanya saf di depannya maka dia tidak mendapatkan keutamaan shalat berjamaah. Beliau berpendapat bahwa seorang jamaah tersebut tidak kehilangan keutamaan shalat berjamaah karena membuat saf baru tersebut.

Pendapat al-Ramli dalam kitab Nihayah al-Muhtaj Ila Syarh al-Minhaj (2/196197):

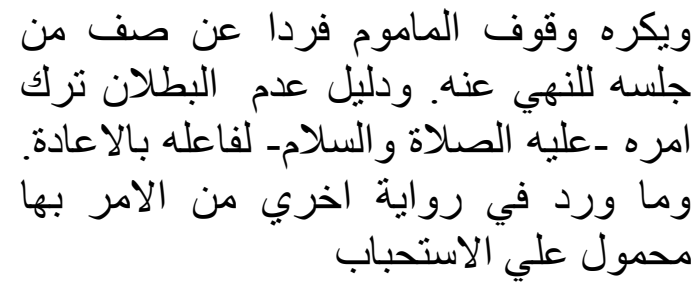

Dan hukumnya makruh bagi makmum yang berdiri sendiri, tetapi tidak sampai membatalkan shalat jamaah karena Rasul Saw. tidak memerintahkannya untuk mengulangi shalat. Adapun perintah Rasul Saw. untuk mengulani shalat (pada riwayat yang lain) adalah dipahami sebagai sesuatu yang disunnahkan.

فان تسوية الصفوف من تمام الصلاة

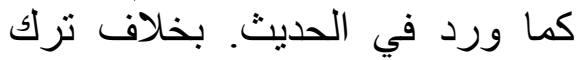

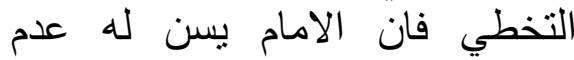

احر امه حتي بسوي بين صفوفهم. نعم

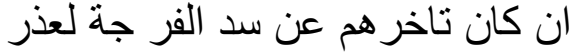

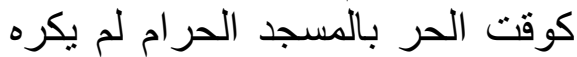

لعد التقصير

Sesungguhnya meluruskan saf adalah termasuk kesempurnaan shalat berjamaah sebagaimana tersebut dalam hadis. Hal ini berbeda jika barisan tidak teratur, maka imam disunnahkan untuk tidak bertakbiratul ihram sebelum meluruskan saf. Jika seseorang tidak 
merapatkan saf karena uzur seperti cuaca panas di masjidil haram, maka tidak makruh karena bukan niat meremehkan.

Pendapat Ibnu Alan As-Shiddiqi alSyafii dalam kitab Dalil al-Falihin (6/573-574):

$$
\begin{aligned}
& \text { وعن انس رضي الله عنه ان رسول الله قال: } \\
& \text { (رصوا صفوفكم) اي حتي لا بيقي فيها }
\end{aligned}
$$

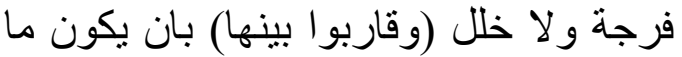

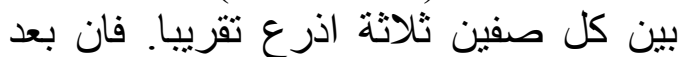

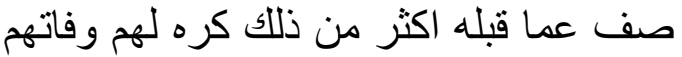

$$
\begin{aligned}
& \text { فضيلة الجماعة حيث لا عذر من حر او برد } \\
& \text { شديد }
\end{aligned}
$$

Dari sahabat Anas ra., Rasulullah Saw. bersabda: "(Susunlah saf kalian) sehingga tidak ada celah dan longgar (dekatkanlah antara keduanya) antara dua saf kurang lebih berjarak tiga hasta. Jika sebuah saf berjarak lebih jauh dari itu dari saf sebelumnya, maka hal itu dimakruh dan luput keutamaan berjamaah sekira tidak ada uzur cuaca panas atau sangat dingin misalnya.

Pendapat Fuqaha terkait dengan pelaksanaan Shalat Jum'at di beberapa tempat, antara lain:

Pendapat Al-Kasani dalam kitab Bada'i al-Shanaai fi Tartib al-Syarai' (1/126):

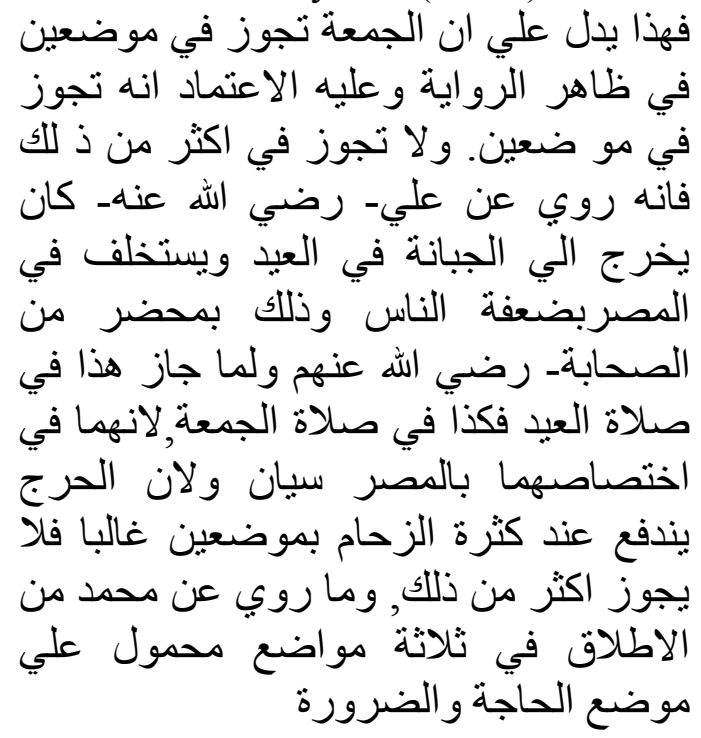

Berdasarkan dzahir riwayat dan pendapat yg dipegang dalam madzhab Hanafi bahwasahnya boleh dilaksanakan shalat Jum'at di dua tempat saja dan tidak boleh lebih dari itu. Diriwayatkan dari Sayyidina Ali bahwa beliau pernah keluar ke lapangan/gurun untuk shalat ied, bersamaan ia mengangkat seseorang sahabat untuk menjadi imam di kawasan kota dan hal tersebut disaksikan para sahabat. Lalu ketika hal ini saja boleh di dalam shalat ied, maka boleh pula di shalat jumat, karena keduanya samasama dilaksanakan satu tempat dalam satu daerah dan karena secara umum kesulitan hilang dengan didirikannnya shalat di dua tempat. Adapun yang diriwayatkan oleh muhammad berupa pemutlakan kebolehan di tiga tempat, itu dimaksudkan untuk keadaan hajat dan darurat.

Pendapat Imam Ibnu 'Abidin dalam kitab Radd al-Mukhtar 'ala alDurri al-Mukhtar (2/144):

$$
\text { (ونؤدي في مصرواحد بمو اضع كثيرة) مطلقا علي الفتوي }
$$

Shalat Jum'at boleh dilaksanakan di banyak tempat dalam satu daerah secara mutlak dalam madzhab Hanafi

Pendapat Imam al-Nawawi dalam kitab al-Majmu' (4/586)

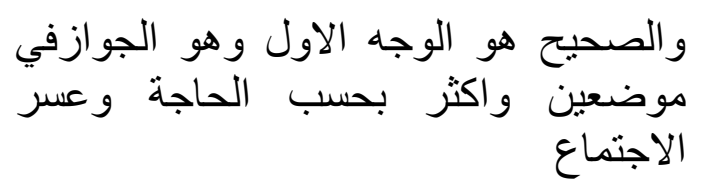

Yang shahih dalam madzhab Syafii adalah bolehnya mengadakan shalat Jum'at pada dua lokasi atau lebih tergantung hajah dan tingkat kesulitan.

Pendapat al-Murawadi dalam kitab alInsaf fi Ma'rifat alRajih min al-Khilaf (2/400)

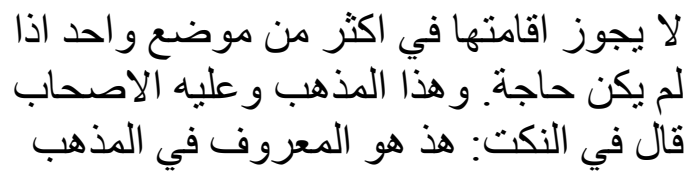
Jika tidak ada hajah, maka tidak boleh melaksanakan shalat jum'at lebih dari satu lokasi. Ini adalah pendapat madzhab Hanbali. 
Pendapat Muhammad Syamsul Haq Abadi dalam kitab 'Aun al-Ma'bud Syarhu Sunan Abi Dawud, Bairut-Dar al-Kutub al- 'Ilmiyyah, Cet ke-2, 1415 H, juz, III, h. 281

$$
\begin{aligned}
& \text { وذهب البعض الي اشتر اط المسجد قال لاتها } \\
& \text { لم تقم الا فيه وقال ابو حنيفة و الشافعي وسائر } \\
& \text { العلماء انه غير شرطو هو قوي }
\end{aligned}
$$

"Sebagian ulama mempersyaratkan masjid sebagai tempat pelaksanaan shalat Jum'at. Sebab, menurut mereka shalat Jumat tidak ada kecuali di masjid. Sedangkan menurut Imam Abu Hanifah, Imam Syafi'i dan mayoritas ulama bahwa masjid bukan syarat bagi pelakasanaan shalat Jumat. Dan ini adalah pendapat yang kuat."

Penjelasan al-Nawawi dalam kitab alMajmu' (4/558):

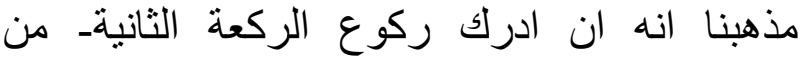

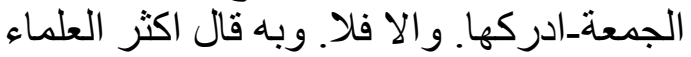

Menurut madzhab Syafii bahwa orang yang ruku'nya imam pada rakaat kedua maka dia shalat Jum'atnya sah dan jika tidak maka shalatnya tidak sah. Ini adalah pendapat jumhur ulama.

Pendapat Fuqaha terkait dengan anggota sujud dan larangan menutup mulut dan wajah saat shalat, antara lain:

Penjelasan Imam al Mawardi dalam kitab al-Hawi al-Kabir (2/126):

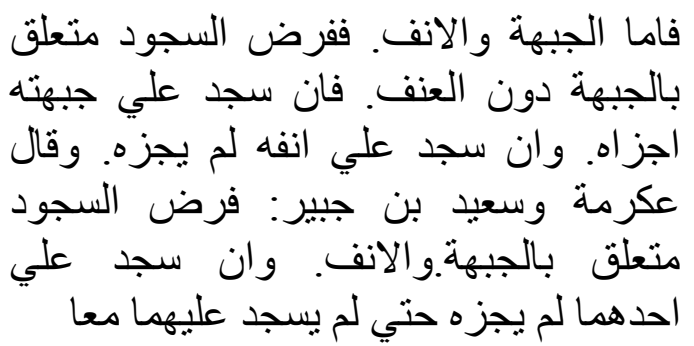

Adapun masalah kening dan hidung, sebenarnya kewajiban sujud itu terkait dengan kening bukan pada hidung. Jika seseorang sujud dengan keningnya maka sah shalatnya dan sebaliknya, jika sududnya dengan hidung maka tidak sah shalatnya. Ikrimah dan Ibnu Jubair berpendapat bahwa kewajiban sujud itu terkait dengan kening dan hidung secara bersama-sama, jika bersujud hanya dengan salah satu keduanya maka tidak sah shalatnya.

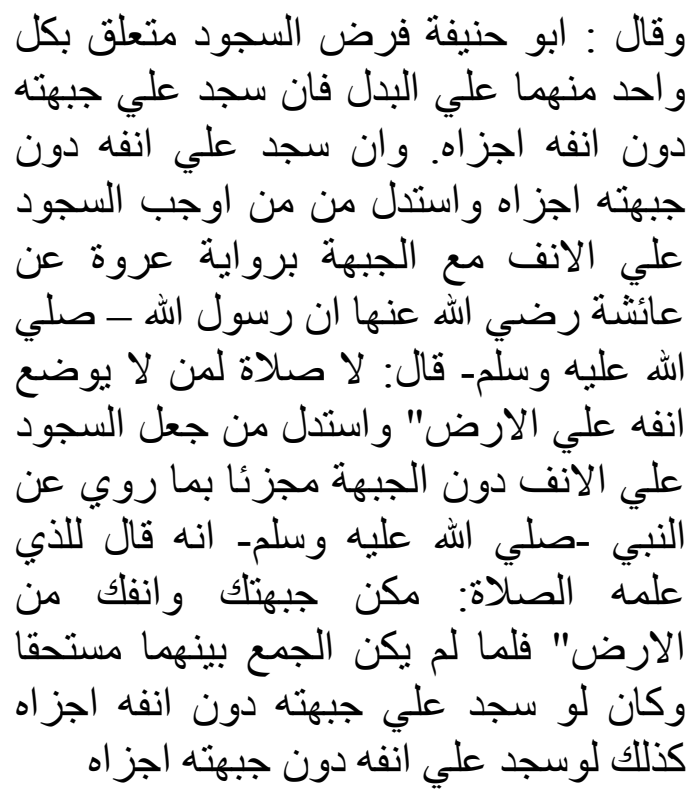

Imam Abu Hanifah berkata: "Kewajiban sujud itu terkait dengan salah satu dari kening dan hidung, maka sah jika bersujud dengan salah satu dari keduanya". Ulama yang berpendapat bahwa anggota badan dalam sujud itu meliputi kening dan hidung berhujjah kepada riwayat hadis yang artinya; "tidak sah shalat seseorang yang tidak menempelkan hidungnya pada tempat sujud". Ulama yang berpendapat bahwa anggota badan saat bersujud itu cukup dengan menempelkan hidung ke tempat sujud tanpa kening berhujjah pada riwayat hadis yang artinya; "tempelkan keningmu dan hidungmu pada tempat sujud saat bersujud". Jika tidak memungkinkan untuk mengumpulkan dua hadis tersebut, maka dianggap sah shalatnya dengan menempelkan salah satu dari kedua anggota tubuh tersebut.

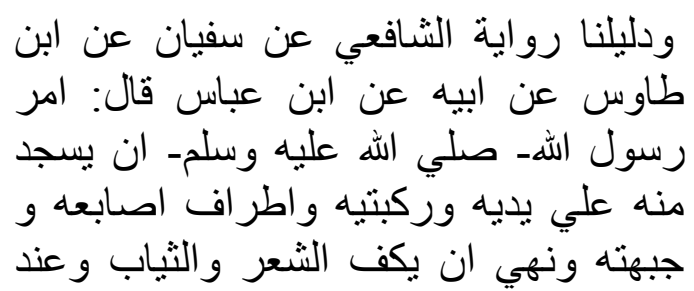


ابي حنيفة :ان كل عضو كان محلا للسجود كان مغنيا ولم يكن مخير ا بينه وبين غيره

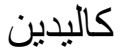

Dalil madzhb Syafii adalah hadis riwayat al-Syafii dari Sufyan dari Ibnu Thawus dari ayahnya dari Ibnu Abbas berkata: "Rasulullah Saw. diperintahkan untuk sujud di atas kedua tangan, kedua lututnya dan ujung jari-jari kakinya, dan dahi dan dilarang untuk menahan rambut dan pakaiannya. Imam Abu Hanifah berpendapat bahwa masalah terkait kening dan hidung itu seperti anggota tubuh saat bersujud yang lainnya yang semua harus menempel pada tempat sujud.

Pendapat al-Nawawi dalam al-Majmu' (3/197) :

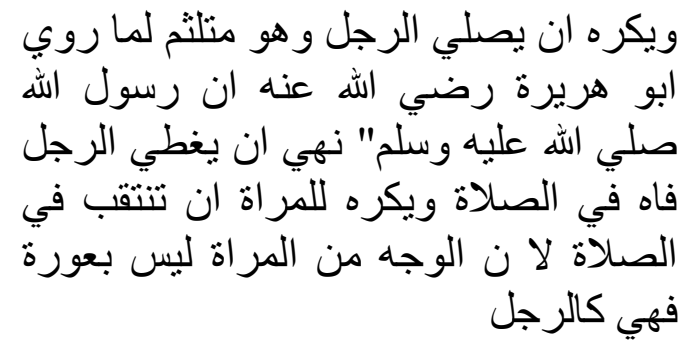

Orang laki-laki dimakruhkan untuk menutup mulutnya saat shalat sebagaimana riwayat dari Abu Hurairah ra. bahwa "Rasulullah Saw. melarang orang laki-laki untuk menutup mulutnya saat shalat". Sedangkan perempuan dimakruhkan untuk memakai cadar saat shalat karena wajah perempuan tidak termasuk aurat saat shalat.

Penjelasan Manshur al-Bahuty dalam kitab Kasysyaf alQanna' (1/268)

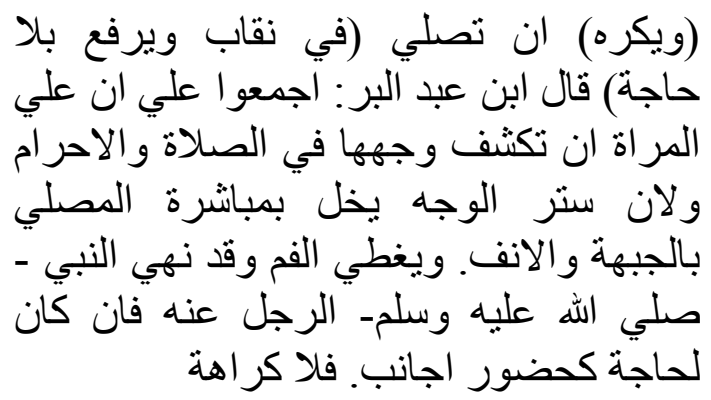

Dalam keadaan tanpa hajah (perempuan dimakruhkan untuk memakai cadar saat shalat), Ibnu Abdi al-Bar berkata: "Ulama bersepakat bahwa perempuan harus membuka wajahnya saat shalat dan ihram, karena menutup wajah menghalangi dahi dan hidung untuk menyentuh tempat sujud". Dan ulama juga bersepakat bahwa laki-laki tidak boleh menutup mulut saat shalat karena adanya riwayat hadis yang melarang laki-laki menutup mulut saat shalat. Jika karena ada hajah seperti hadirnya orang yang bukan muhrim maka tidak dimakruhkan.

Dari pemaparan istidlal fatwa MUI di atas maka dapat penulis katakan bahwa istidlal atau istinbathul ahkam MUI terkait dengan fatwa Covid 19 adalah sebagai berikut:

Pertama Ayat al Al Quran surah al Jumu'ah ayat 9, al Baqarah ayat 43 , an nisa 102, al Hajj ayat 77, al Baqarah ayat 195 dan 185, al haj ayat 78, at Thagabun 16, ayat -ayat di atas kebanyakan terkait dengan kewajiban shalat Jum'at dan wajibnya Shalat serta adanya rukhsah dan keringanan dalam Islam, serta menjelaskan bahwa Allah Swt menghendaki kemudahan dalam melaksanakan beribadah bukan menyulitkan atau memberatkan dalam menjalankan ibadah bagi mukallaf.

Kedua Hadis, yakni hadis Riwayat Abu dawud, hadis Riwayat Bukhari, Riwayat Ibnu Majah, Riwayat Muslim, Riwayat Baihaqi, Riwayat Ahmad, Riwayat ad Daruquthni, al baihaqi dan al hakim,

ketiga: Atsar Sahabat yakni bersumber dari Riwayat musonnaf Abdurrazaq as shon'ani

Keempat: Qaidah Fiqhiyah yakni ada enam kaidah fiqhiyah yang intinya terkait adanya keringanan dalam beribadah selagi ada hajat atau ada kebutuhan atau kedharuratan

Keenam: Pendapat para ulama. Yakni ar Ramli dari madzhab Syafei, Ibnu Alan Ash Shiddiqi al Syafei, dari madzhab Syafei, al Kasani dari madzhab Hanafi, Syaikh Ibnu Abidin 
dari madzhab Hanafi, Imam Nawawi dari madzhab Syafei, Syaikh al Murawad, Syaikh Muhammad Syamsul Haq Abadi, Imam Nawawi dari madzhab Syafei, imam al Mawardi dari madzhab Syafei, Imam Nawawi dari madzhab Syafei, Syaikh Manshur al Bahuty

Dari urutan di atas sebenarnya dapat dikatakan bahwa fatwa tersebut sudah memenuhi syarat dalam beristidlal sesuai dengan pendapat jumhur ulama.

\section{KESIMPULAN}

Istidlal atau Istinbathul ahkam yang dilakukan MUI dalam mengeluarkan fatwa no. 31 tahun 2020 adalah: dapat dikatakan bahwa istidlal MUI terkait dengan fatwa Covid 19 adalah sebagai berikut: Pertama Ayat al Al Quran surah al Jumu'ah ayat 9, al Baqarah ayat 43, an nisa 102, al Hajj ayat 77, al Baqarah ayat 195 dan 185, al haj ayat 78, at Thagabun 16, ayat -ayat di atas kebanyakan terkait dengan kewajiban shalat Jum'at dan wajibnya Shalat serta adanya rukhsah dan keringanan dalam Islam, serta menjelaskan bahwa Allah Swt menghendaki kemudahan dalam melaksanakan beribadah bukan menyulitkan atau memberatkan dalam menjalankan ibadah bagi mukallaf.Kedua Hadis, yakni hadis Riwayat Abu dawud, hadis Riwayat Bukhari, Riwayat Ibnu Majah, Riwayat Muslim, Riwayat Baihaqi, Riwayat Ahmad, Riwayat ad Daruquthni, al baihaqi dan al hakim, ketiga: Atsar Sahabat yakni bersumber dari Riwayat musonnaf Abdurrazaq as shon'aniKeempat: Qaidah Fiqhiyah yakni ada enam kaidah fiqhiyah yang intinya terkait adanya keringanan dalam beribadah selagi ada hajat atau ada kebutuhan atau kedharuratan Keenam: Pendapat para ulama. Yakni ar Ramli dari madzhab Syafei, Ibnu Alan Ash Shiddiqi al Syafei, dari madzhab Syafei, al Kasani dari madzhab Hanafi, Syaikh Ibnu Abidin dari madzhab Hanafi,
Imam Nawawi dari madzhab Syafei, Syaikh al Murawad, Syaikh Muhammad Syamsul Haq Abadi, Imam Nawawi dari madzhab Syafei, imam al Mawardi dari madzhab Syafei, Imam Nawawi dari madzhab Syafei, Syaikh Manshur al Bahuty. Dari urutan di atas sebenarnya dapat dikatakan bahwa fatwa tersebut sudah memenuhi syarat dalam beristidlal sesuai dengan pendapat jumhur ulama.

\section{DAFTAR PUSTAKA}

Abdurahman, Asjmuni. 2003. Qawa'id Fiqhiyyah: Arti, Sejarah, dan Beberapa Qa'idah Kulliyah. Yogyakarta: Suara Muhammadiyah.

Abu Sulaiman, Abdul Wahhab Ibrahim. Pengaruh Dharurat dan Hajat

Dalam Hukum Islam (Al-

Dharurah wa Al-Hajah wa

Atsaruhuma fi Al-Tasyri' Al-

Islami).Terjemahan oleh Said

Agil Husain Al-Munawar \& Hadri

Hasan. Semarang: Dina

Utama, 1994

Ad Duraini, Muhammad Fathi, al Manahij al Ushuliyah Fil Ijtihad Bir ro'yi Fit Tasyri al Islami cet ke 3 Beirut: Muassasah ar Risalah, 1997

Al Amidi, Saif al din, Al Ihkam Fi Ushul al Ahkam, Jilid 3, Beirut: Dar al Fikr,1996,

Al Bayanuni Muhammad Abdul Fatah, Fikih Darurat (Fiqh ad Dharuroh: ma'alimuhu wa Dhawabituhu) Terj. Abdul Majid , Jakarta, Turos, 2018

Al Ghazali, Abi Hamid Muhammad bin Muhammad bin Muhammad, Al Mustashfa Fi ilmil Ushul, Beirut: Dar al Kutub Al ilmiyah, 1996 
Al Jurjani, Ali bin Muhammad bin Ali, At Ta'rifat, Beirut: Dar al kutub al ilmiyah, 1983

Al Malibari Zainudin Fathul Muin Indonesia: Menara Kudus, 1980

Al Šafi'I Muhammad bin Aidris al Risalah Mesir: Matba'ah al Halabi, t.th

Al Syatbi, Abu Ishaq Ibrahim bin Musa, al-I'tisham, Jilid II Mesir: alMaktabah al- Tijariyah al- Kubra, t.th.

Al-Bûthì, Muhammad Sa'ìd Ramadlân Dawâbith al-Mashlahahfisyarìah al-Islâmiyyah, Beirut: Muassasah al-Risâlah, 1990

Al-Munawar, Said AgilHusein, “ Madzhab dalamPandangan $N U$, Fikih, dan Teologi", Aula, no. 8, September 1992,

Al-Sarakshi, Syamsudin, Ushul alSarakhshi, Beirut: Dar al-Kutub al-'Ilmiyyah, 1993

Al-Syatibi, Abu Ishaq, Al Muafaqat $f i$ ushul al-Syari'ah, Jilid IV Beirut: Dar al-Ma'rifah, 1975,

Al-Zuhaili, Wahbah, Konsep Darurat Dalam Hukum Islam: Studi Banding dengan Hukum Positif (Nazhariyyah Al-Dharurah AlSyar'iyah Muqaranatan Ma'a AlQanun Al-Wadh'i). Terjemahan oleh Said Agil Husain AlMunawar \& Hadri Hasan. Jakarta: Gaya Media Pratama. 1997.

Al-Zuhaylī, Wahbah, Ușūl al-Fiqh alIslāmī, jilid II, cet. 1, Damaskus: Dār al-Fikr al-Mu'āṣir, 1986.

Amir, Dja'far, Qaidah-Qaidah Fiqih. Semarang: Ramadhani, tth.
As-Suyuthi, Jalaluddin. Tanpa Tahun. Al-Asybah wa An-Nazha ir fi AlFuru'. Semarang: Toha Putera.

Azzam , Abdul Aziz Muhammad, FiqhMuamalat, Jakarta: Amzah, 2010

Ensiklopedi Hukum Islam, jilid 3, Jakarta: IkhtiarBaru Van Hoeva, 1997

Eriyanto, AnalisisWacana: PengantarAnalisisTeks Media, Yogyakarta: LKiS, 2001,

Fatwa MUI No. 31 Tahun 2020 www.mui.or.id

Harun, Nasrun,Ushul Fiqh 1, (Jakarta: Logos.1996), cet. 1, h. 62.

Haryono, Anwar, Hukum Islam keluwesan dan Keadilannya. Jakarta: Bulan Bintang, 1968

Ibnu Mandzur, Lisanul Arab, (Beirut: Dar al Fikr,1972), Bab Sin, Juz. 6, h. 354 .

Ibnu Nujaim, Zainal Abidin ibn Ibrahim al Hanafi, al Asybah wa al Nazhair, Damaskus: Dar al Fikr, 1983, cet. ke-1

Ibnu Qosim, Muhammad, Fathul Qorib al Mujib, Indonesia: Dar ihya al Kutub, tth

Johari, Pembaharuanhukum Islam (StudiPerubahan fatwa Ibnuqayyim al-Jauziyyah);Tesis, IAIN Sunan Kali Jaga, Yogyakarta, 2004

Kholaf, Abdul Wahab, Ilmu Ushul al fiqh, Kairo: Matba'ah an Nasr, 1956 
Mahmud Syaltut, al fatawa dirosah $l i$ musykilatil muslim al muashir fi hayatihi al yaumiyah wal ammah Mesir: Dar al Qalam, tth

Mudjib Abdul , Kaidah-kaidah Ilmu Fiqh, Jakarta: Kalam Mulya, 2005

Muhlish, Usman,. Kaidah-Kaidah Ushuliyah dan Fiqhiyah. Jakarta: Raja Grafindo Persada. 1996

Munawwir, Ahmad Warson. Kamus AlMunawwir. Cet. Ke-1. Yogyakarta: PP. Al-Munawwir Krapyak. 1984.

Pedoman Penyelenggara Organisasi MajelisUlama Indonesia,

Sholeh, Asrorun Ni'am, Metodologi Penetapan Fatwa Majelis Ulama Indonesia Jakarta: Emir, 2016

Syarifudin, Amir, Ushul Fiqh 2 cet. 2 ,Jakarta: Logos Wacana Ilmu, 2001

Taneko,Soeleman B. Pokok-pokokstudi Islam dalamMasyarakat, Jakarta: Raja grafindoPersada, 1993

Ulum, Bahrul, Ulama dan Politik, NalarPolitikKebangsaanMajelis Ulama Indonesia, Yogyakarta, PustakaPelajar, 2015,

Wahid, Abdurrahman, PengembanganFikih yang kontekstual. DalamPesantren Jurnal No. 2/Vol. II. 1985.

Zaidan, Abdul Karim, Al Wajiz fi Ushul Fiqih, Iraq: Dar at Taizi' Wa nasyar al Islamiyah, 1993 